\title{
A Response Surface Approach for Determining Optimal Mix Parameters for Normal Strength Concrete
}

\author{
Kareem, M.A., Bamigboye, G.O., Olawale, S.O.A., Tijani, M.A., Ishola, K. and Olawuyi, O. A.
}

\begin{abstract}
The study evaluates the influence of water/cement ratios and aggregates contents on the engineering properties of normal weight concrete. Response Surface Methodology (RSM) using historical design was adopted to design and develop predictive models and perform the optimization of concrete prepared with cement, fine aggregate (FA), coarse aggregate (CA) contents at different water/cement ratio $(\mathrm{W} / \mathrm{C})$ by volume. Concrete mixes were prepared using fixed content of ordinary Portland cement and the different mixtures. The density and compressive strength of hardened concrete specimens were determined at the curing 28 days. The response surface analysis showed that $\mathrm{W} / \mathrm{C}$ and aggregate contents have significant effects on density and compressive strength of concrete. The regression model yielded good correlations with the experimental data. The optimized density and 28-day compressive strength values of 2522.973 $\mathrm{kg} / \mathrm{m}^{3}$ and $29.977 \mathrm{~N} / \mathrm{mm}^{2}$ were achieved for the concrete mix containing 1.5-part of FA, 3-part of $\mathrm{CA}$ and $0.60 \mathrm{~W} / \mathrm{C}$, respectively. The optimal concrete mix parameters determined using RSM provides the basis for selecting appropriate safe concrete component ratios.
\end{abstract}

Keywords: Mix proportion, Prediction, Water-cement ratio, Compressive strength, Regression model

\section{Introduction}

Concrete is the most widely used construction material that is found applicable in virtually all structural works worldwide [1]. It is the most suitable material for the construction of structural elements where strength, durability, impermeability, fire resistance and abrasion resistance is required [2]. Normal weight concrete is a composite material which has cement, aggregates (fine and coarse) and water as its constituent materials. These materials are combined in a specific ratio, which is determined by its usage. Improvement in the strength of concrete can only be imputed during its formation and never after worth.

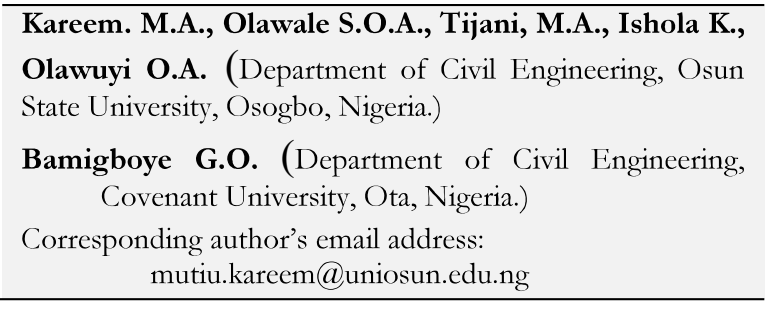

Cement and aggregate types, strength and quality as well as their mixing ratio and construction condition are the factors causing variations in the strength of concrete[3]. Aggregate are essential constituents of concrete, which define its workability, thermal and elastic properties, dimensional stability and durability, thus, the strength of concrete is influenced by the mix proportions of concrete constituents adopted and also the aggregate contents which can be varied up to $80 \%$ by weight or volume of concrete [4]. W/C is essential for the overall performance of concrete. In the presence of water, the hydration process of concrete or mortar is enhanced which is in turn, results to gain of strength and increase in durability with the passage time.

Kheder et al. [5] emphasized the need to determine reliable prediction for the strength of concrete without waiting for 28 day's strength to improve the rapidity of construction and determination of the quality of concrete that 
conforms to concrete standards and specifications. This will provide the chance to make vital changes in the mix proportion used so as to avoid unwanted conditions such as low design strength or excessive design strength for economical construction cost. Besides, early prediction of concrete helps to schedule operations such as pre-stressing and removal of formwork. This prediction can lead to an increase in speed of construction and contribute to quality control [6].

Previous studies $[5,7,8,9,10]$ have proposed different regression model for the prediction of concrete strength by considering different characteristics and proportioning of the concrete constituents which influence the behaviour of concrete. The singular objective of the researchers was to predict the concrete strength and to validate the mathematical model after the prediction. Most of the proposed prediction model is based on the relationship between concrete strength and its constituent characteristics [11].

RSM is a collection of mathematical and statistical techniques useful for the modelling and analysis of problems in which a response of interest is influenced by several variables $[12,13]$. RSM is a tool found to be useful in many industries and the popularity has been extended to the construction industries since the various constituents of the major construction material such as mortar, concrete, asphalt is greatly influenced by their respective constituent materials [13]. User-defined, historic data, central composite and D-optimal models are some of the available models in RSM. However, the selection of model type is based on the nature and the number of levels of variables [14].

The study of [15] predicted the water absorption and compressive strength of concrete produced by partial replacement of walnut for fine aggregates using RSM. The study of [16] evaluated the effects of curing duration and methods and periwinkle shell on the compressive strength of concrete using RSM. The study of [17] determined the optimal raw material mix for the production of blended cement using RSM. The study of [14] developed a model for predicting the tensile properties of self-consolidating engineered cementitious composite wit nano-silica and polyvinyl alcohol. The use of RSM provides the opportunity for better understanding of the interaction of the mixture components with several responses which cannot be possibly understood with the use of conventional methods.

Also, the numerical optimization perform with RSM yielded good results which are efficient for prediction of experimental results due to their multi-parameters. Thus, this study employed the use of RSM to evaluate the effect of the constituent material of normal weight concrete on its density and compressive strength at $28^{\text {th }}$ day of curing. In addition, the regression models for prediction of density and compressive strength at $28^{\text {th }}$ day of curing were developed and the optimum mixing parameters were identified.

\section{Materials and Methods}

\section{A. Materials}

The coarse aggregates used in this research were crushed granite of $20 \mathrm{~mm}$ maximum size obtained from aggregates supplier within Ogbomoso, Nigeria. River sand with $40 \%$ particles passing 600 microns sieve was used as fine aggregates. Elephant brand of ordinary Portland cement of grade $32.5 \mathrm{~N}$ (CEM II), a brand which conforms to [18] was used as the binder in this study. The cement was procured from the retail shops within Ogbomoso. The water used in the research was collected from public water supply within Ladoke Akintola 
University of Technology, Ogbomoso, Oyo State, Nigeria.

\section{B. Design of Experiment and Statistical Analysis}

The effect of fine aggregate, coarse aggregate contents and water/cement ratio was studied using historical design coupled with RSM. This was executed using Design-Expert Version 10.0.1, 2010 (Stat-Ease, Inc.) software. Eighteen (18) mixtures containing three factors (water/cement ratio, fine aggregate content and coarse aggregate content) in the range listed in Table 1. The polynomial equation that correlates the compressive strength/density to the concrete parameters by linear, quadratic, cubic and interaction terms is shown in Equation (1).

$$
E(Y)=\eta=\sum_{i=1}^{q} \beta_{i} x_{i}+\sum_{i<j}^{q} \beta_{i j} x_{i} x_{j}+\epsilon \quad n
$$

where $\mathrm{n}$ is the number of responses in the measure, $x$ is the mixture component, $\beta$ is a constant and $\epsilon$ is a random error term.

Different models (linear, two factorial interaction (2FI), quadratic, cubic, quartic, fifth and sixth interaction) models were used to analyze the properties of concrete as affected by the mixture constituents; the models were fitted into the experimental data using Design-Expert Version 10.0.1, 2010 (Stat-Ease, Inc.). The appropriate model was selected based on the lowest standard deviation values, the highest coefficient of determination where the additional terms are significant [19]. The analysis of variance (ANOVA) was used to determine the level of significant variables and their interactions based on the value is $\mathrm{p}$-value of 0.05 . The regression analysis generated the predictive models (equations) with some coefficients, which depend on the contribution of each factor. Subsequently, the optimum mixing parameters were identified using the model developed.

\section{Concrete Mixes Preparation and Curing} Concrete mixes of a grade of $20 \mathrm{~N} / \mathrm{mm}^{2}$ were prepared using fixed content of ordinary

Table 1. Factors and Levels adopted for Historical Data Design used to prepare Concrete Mix

\begin{tabular}{lcc}
\hline \multirow{2}{*}{ Factor } & \multicolumn{2}{c}{ Level (volume fraction) } \\
\cline { 2 - 3 } & Minimum & Maximum \\
\hline W/C & 0.35 & 0.6 \\
FA & 1.50 & 3.0 \\
CA & 3.00 & 6.0 \\
\hline
\end{tabular}

Table 2. Experimental Results of Responses of Density and Compressive Strength

\begin{tabular}{cccccc}
\hline $\begin{array}{c}\text { Run } \\
\text { Order }\end{array}$ & \multicolumn{3}{c}{ Factors } & \multicolumn{2}{c}{ Responses } \\
\cline { 2 - 6 } & W/C & FA & CA & $\begin{array}{c}\text { Density } \\
\left(\mathbf{k g} / \mathbf{m}^{3}\right)\end{array}$ & $\begin{array}{c}\text { Compressive } \\
\text { strength } \\
\left(\mathbf{N} / \mathbf{m m}^{2}\right)\end{array}$ \\
\hline 1 & & & & 2726 & 29.93 \\
2 & 0.35 & 1.5 & 3 & 2548 & 28.00 \\
3 & 0.45 & 1.5 & 3 & 2607 & 30.20 \\
4 & 0.50 & 1.5 & 3 & 2430 & 29.24 \\
5 & 0.55 & 1.5 & 3 & 2489 & 30.00 \\
6 & 0.60 & 1.5 & 3 & 2578 & 29.78 \\
7 & 0.35 & 2.0 & 4 & 2311 & 15.44 \\
8 & 0.40 & 2.0 & 4 & 2352 & 16.56 \\
9 & 0.45 & 2.0 & 4 & 2411 & 17.23 \\
10 & 0.50 & 2.0 & 4 & 2370 & 16.21 \\
11 & 0.55 & 2.0 & 4 & 2408 & 16.14 \\
12 & 0.60 & 2.0 & 4 & 2341 & 16.96 \\
13 & 0.35 & 3.0 & 6 & 2311 & 13.26 \\
14 & 0.40 & 3.0 & 6 & 2394 & 12.92 \\
15 & 0.45 & 3.0 & 6 & 2370 & 13.64 \\
16 & 0.50 & 3.0 & 6 & 2393 & 13.00 \\
17 & 0.55 & 3.0 & 6 & 2322 & 11.98 \\
18 & 0.60 & 3.0 & 6 & 2400 & 14.20 \\
\hline
\end{tabular}

Table 3. ANOVA for Response Surface Quadratic model for Density

\begin{tabular}{lccc}
\hline Source & Sum Squares & df & Mean Square \\
\hline Model & $1.687 \mathrm{E}+005$ & 5 & 33738.72 \\
W/C & 653.020 & 1 & 653.02 \\
FA & $1.176 \mathrm{E}+005$ & 1 & $1.176 \mathrm{E}+005$ \\
CA & 0.000 & 0 & \\
W/C * FA & 9768.330 & 1 & 9768.33 \\
W/C *CA & 0.000 & 0 & \\
FA $*$ CA & 66698.680 & 1 & 66698.68 \\
$(W / C)^{2}$ & 984.140 & 1 & 984.14 \\
$(\mathrm{FA})^{2}$ & 0.000 & 0 & \\
$(\mathrm{CA})^{2}$ & 0.000 & 0 & \\
Residual & 55136.910 & 12 & 4594.74 \\
Cor Total & $2.238 \mathrm{E}+005$ & 17 & \\
\hline
\end{tabular}


Table 4. ANOVA for Response Surface Quadratic model for 28-day compressive strength

\begin{tabular}{lcccccc}
\hline \multicolumn{1}{c}{ Source } & Sum Squares & df & Mean Square & F Value & p-value Prob $>$ F & \\
\hline Model & 900.430 & 5 & 180.090 & 290.27 & 0.0001 & significant \\
W/C & 0.490 & 1 & 0.490 & 0.80 & 0.3901 & \\
FA & 802.79 & 1 & 802.790 & 1293.97 & 0.0001 & \\
CA & 0.000 & 0 & & & & \\
W/C * FA & 0.090 & 1 & 0.090 & 0.15 & 0.7097 & \\
W/C * CA & 0.000 & 0 & & & & \\
FA $*$ CA & 225.66 & 1 & 225.660 & 363.74 & 0.0001 & \\
$(\text { W/C })^{2}$ & 0.069 & 1 & 0.069 & 0.11 & 0.7445 & \\
$(\mathrm{FA})^{2}$ & 0.000 & 0 & & & & \\
$(\mathrm{CA})^{2}$ & 0.000 & 0 & & & & \\
Residual & 7.440 & 12 & 0.620 & & & \\
Cor Total & 907.870 & 17 & & &
\end{tabular}

Table 5. Range of components and responses for desirability

\begin{tabular}{clccccc}
\hline Name & Goal & $\begin{array}{c}\text { Lower } \\
\text { Limit }\end{array}$ & $\begin{array}{c}\text { Upper } \\
\text { Limit }\end{array}$ & $\begin{array}{c}\text { Lower } \\
\text { Weight }\end{array}$ & $\begin{array}{c}\text { Upper } \\
\text { Weight }\end{array}$ & $\begin{array}{c}\text { Importance } \\
\text { W/C }\end{array}$ \\
FA & maximize & 0.35 & 0.6 & 1 & 1 & 3 \\
CA & minimize & 1.50 & 3.0 & 1 & 1 & 3 \\
Density & Minimize & 3.00 & 6.0 & 1 & 1 & 3 \\
28-Compressive Strength & Minimize & 2311 & 2726 & 1 & 1 & 3 \\
B:FA & Maximize & 11.98 & 30.2 & 1 & 1 & 3 \\
C:CA & minimize & 1.50 & 3.0 & 1 & 1 & 3 \\
Density $\left(\mathrm{kg} / \mathrm{m}^{3}\right)$ & minimize & 3.00 & 6.0 & 1 & 1 & 3 \\
28-dayCompressive Strength & minimize & 2311 & 2726 & 1 & 1 & 3 \\
\hline
\end{tabular}

Table 6. Optimal set of condition with the highest desirability

\begin{tabular}{llllll}
\hline W/C & FA & CA & $\begin{array}{l}\text { Density } \\
\left(\mathbf{k g} / \mathbf{m}^{3}\right)\end{array}$ & $\begin{array}{l}\text { Compressive } \\
\text { strength } \\
\left(\mathbf{N} / \mathbf{m m}^{2}\right)\end{array}$ & Desirability \\
\hline 0.600 & 1.500 & 3.000 & 2522.973 & 29.977 & 0.865 \\
\hline
\end{tabular}

Portland cement and the different mixtures designed.

Batching by volume was employed to prepare the sample before mixing each of the eighteen different mixtures in Table 2. Mixing of the constituent materials was done manually. Specimens used for the compressive strength test were cast using $150 \mathrm{~mm}$ cubic size moulds. For each of the concrete mix, three concrete specimens were prepared and a total of 54 concrete specimens were cast for eighteen different mixtures in Table 2. After casting, the specimens were stored in the curing room at 27 $\pm 5^{\circ} \mathrm{C}$ with $90 \%$ relative humidity for $24 \mathrm{~h}$ and then demoulded and placed inside curing tank until the testing ages of 28 days.

\section{Testing Methods}

Density and compressive strength tests were carried out on the concrete specimens as specified in $[20,21]$. These tests were carried out at the Structural Laboratory, Department of Civil Engineering, Ladoke Akintola University of Technology, Ogbomoso, Nigeria.

\section{Results and Discussion}

The factors combinations comprising of eighteen experimental (mixtures) runs as generated by Design Expert (version 10.0.1, 2010) software and the experimental results are shown in Table 2. 


\section{A. Density of Concrete}

\section{1) Experimental Results}

The results of the average density for the concrete specimens for the eighteen concrete mixes are presented in Table 2.

The results revealed that the 28-day density of the hardened specimens seemed to decrease as aggregate content decreases by an average of $8 \%$ at low $\mathrm{W} / \mathrm{C}$. The decrease in the mean density as aggregates/cement ratio decreases is an indication that aggregate content in concrete contributes significantly to the density which is line with the previous findings reported by $[2$, 22-23]. The highest mean density of $2726 \mathrm{~kg} / \mathrm{m}^{3}$ was obtained for concrete mix 1 with mix ratio 1:1.5:3 and W/C of 0.35 at 28 days while the lowest mean density of $2311 \mathrm{~kg} / \mathrm{m}^{3}$ was obtained for concrete mix 7 and 13 with mix ratio 1:2:3 and $1: 3: 6$, respectively with $\mathrm{W} / \mathrm{C}$ of 0.35 at 28 days.

\section{2) RSM Results for Density}

The experimental results in Table 2 were analyzed using RSM to model and optimize the impact of W/C, FA and CA on concrete density. Table 3 shows the summary of ANOVA for the responses of the Density of concrete mixes. The correlation coefficient R-squared $=75.37 \%$ of the models from the analysis of experimental data are efficient for the prediction of concrete density. The corresponding polynomial equation estimated from the model is represented in Equation 2:

$$
\begin{array}{r}
D_{28}=2307.42-8.9 \mathrm{~W} / \mathrm{C}-99 \mathrm{FA}+41.01(\mathrm{~W} / \mathrm{C})(\mathrm{FA})+ \\
147.94(\mathrm{FA})(\mathrm{CA})+18.53(\mathrm{~W} / \mathrm{C})^{2}
\end{array}
$$

where $D_{28}$ is the Density of concrete at 28-day curing age.
Figure 1 showed the 3D response surface plots of the interactive effects of the mix parameters on the density of concrete keeping all other factors constant. The Figure revealed that as the $\mathrm{W} / \mathrm{C}$ increases, the density of concrete increases with an increase in FA while the increase in W/C ratio showed no significant influence on the density of concrete as the CA increases. However, the density of concrete decreases with a decrease in CA as FA increases. The minimum density of concrete was achieved with the W/C ratio of 0.5 while the maximum was achieved with $0.6 \mathrm{~W} / \mathrm{C}$ ratio as shown in (Figure 1(b)). The decrease in the density of concrete as the CA content increases is an indication that CA is ofhigher specific gravity compared to FA which results to the declining trend of density concrete which is in line with the findings of [24].

\section{B. Compressive Strength}

\section{1) Experimental Results}

The results in Table 2 revealed a decreasing trend in the 28-day compressive strength of the hardened specimens as the aggregate contents increases at low $\mathrm{W} / \mathrm{C}$. The result indicated that the highest mean compressive strength at 28 days of $30.20 \mathrm{~N} / \mathrm{mm}^{2}$ which was obtained for concrete specimen with concrete mix sample 3 with W/C of 0.45 at 28 days curing age while the lowest mean compressive strength of 11.98 $\mathrm{N} / \mathrm{mm}^{2}$ was obtained for concrete mix 17 with $\mathrm{W} / \mathrm{C}$ of 0.55 at 28 days. The decrease of an average of $33 \%$ in the mean compressive strength as aggregates-to-cement ratio decreases is an indication that aggregate-to-cement ratio contributes significantly to the compressive strength of concrete which is line with the previous findings [2, 23-24]. 


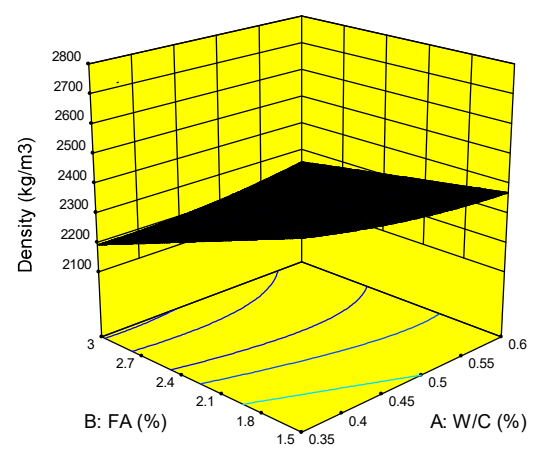

(a) $\mathrm{FA} * \mathrm{~W} / \mathrm{C}$

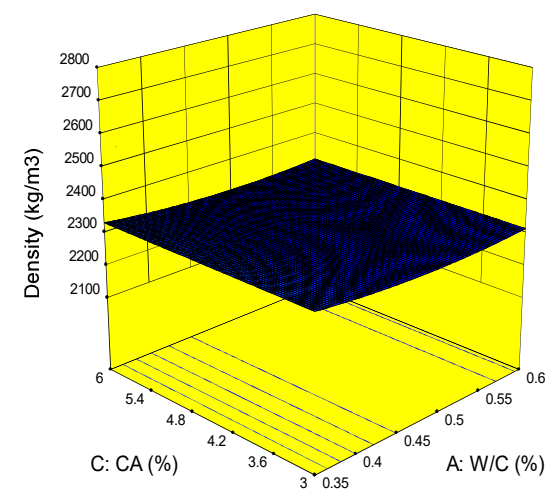

(a) $\mathrm{CA} * \mathrm{FA}$

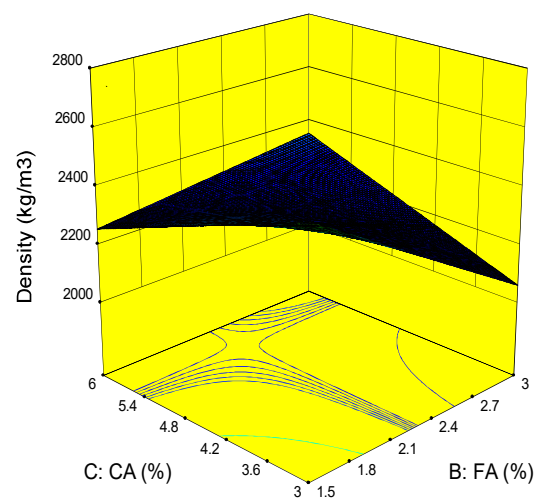

(a) $\mathrm{CA} * \mathrm{FA}$

Figure 1: Response surface plots for the effect of different mix parameters on the density of concrete

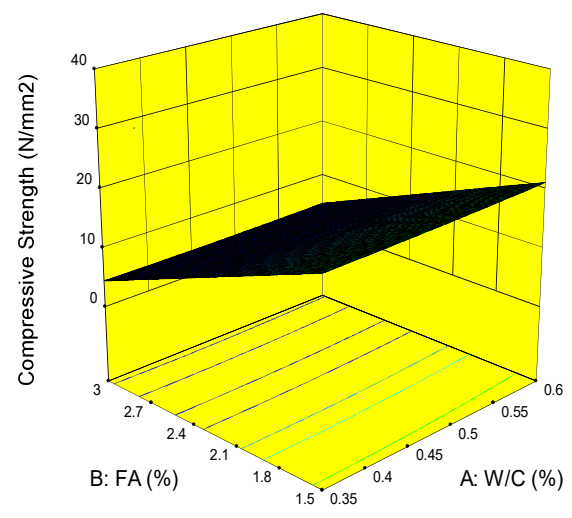

(a) $\mathrm{FA} * \mathrm{~W} / \mathrm{C}$

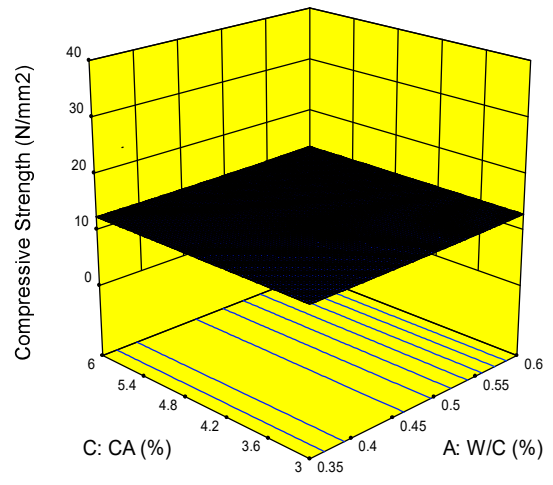

(b) $\mathrm{CA} * \mathrm{FA}$

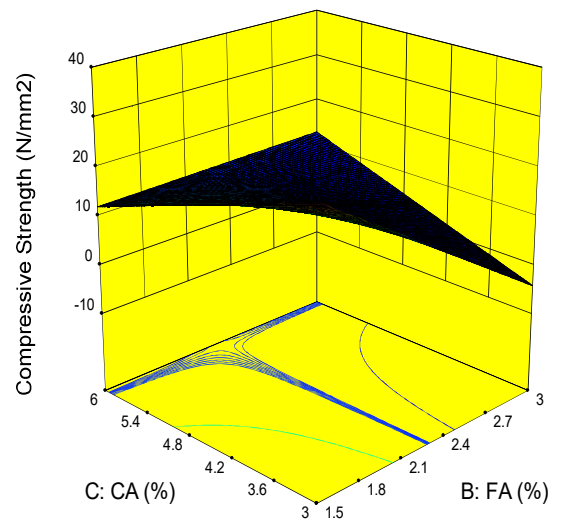

(c) $\mathrm{CA} * \mathrm{FA}$

Figure 2: Response surface plots for the effect of different mix parameters on the compressive strengthof concrete. 


\section{2) RSM Results for Compressive Strength}

The experimental results in Table 2 were analyzed using RSM to model and optimize the impact of W/C, FA and CA on concrete 28-day compressive strength. Table 4 shows the summary of ANOVA for the responses of the Density of concrete mixes. The correlation coefficient R-squared $=99.18 \%$ of the models from the analysis of experimental data is efficient for the prediction of concrete density. The corresponding polynomial equation estimated from the model is represented in Equation 3:

$\mathrm{CS}_{28}=12.67-0.24 \mathrm{~W} / \mathrm{C}-8.81 \mathrm{CA}+0.12(\mathrm{~W} / \mathrm{C})(\mathrm{FA})+$

$8.16(\mathrm{FA})(\mathrm{CA})+0.16(\mathrm{~W} / \mathrm{C})^{2}$

where $\mathrm{CS}_{28}$ is the compressive strength of concrete at 28-day curing age.

The relationships between the mix parameters on 28-day compressive strength of concrete keeping all other factors constant were demonstrated in Figure 2. The Figure revealed that as the W/C increases, the 28-day compressive strength of concrete increases with an increase in $\mathrm{FA}$ while the increase in $\mathrm{W} / \mathrm{C}$ ratio showed no significant influence on 28-day compressive strength of concrete as the CA increases. However, the 28-day compressive strength of concrete decreases with a decrease in $\mathrm{CA}$ as FA increases. The decrease in the 28-day compressive strength with increase in FA content is attributed to the poor fluidity which causes the void ratio to increase resulting in lower compressive strength of the concrete mixtures [15].

\section{Optimization of the Mixture Constituents of the Concrete}

Upon generating equations relating the factors and responses, the concrete components $\mathrm{FA}$, $\mathrm{CA}$ and $\mathrm{W} / \mathrm{C}$ were optimized for density and Compressive strength. The optimization results were generated based on the constraints of individual characteristics [17] as shown in Table 5. The set of condition with the highest desirability is selected as the optimum condition for the normal weight concrete as presented in

\section{Conclusions}

From the findings of this study, the following conclusions are made:

(i) The mix proportion of elements of concrete affects the density and the compressive strength of the mix as the density and compressive strength of concrete decreases with a decrease in CA contents.

(ii) The models were able to predict the density and compressive strength of normal weight concrete at 28 days curing age with an adjusted coefficient of determination $\left(\mathrm{R}^{2}\right)$ of 0.9918 and 0.7737 .

(iii) The optimum compressive strength of $30.20 \mathrm{~N} / \mathrm{mm}^{2}$ at 28 days curing age was achieved for the concrete mix with1.5and 3 by volume and $\mathrm{W} / \mathrm{C}$ ratio of 0.45 respectively.

(iv) The mix proportion of elements of concrete affects the density and the compressive strength of the mix as the density and compressive strength of concrete decreases with a decrease in CA contents.

(v) Numerical optimization determined the optimum concrete mixing parameters of 1.5 part of FA, 3 part of $\mathrm{CA}$ and $0.60 \mathrm{~W} / \mathrm{C}$, respectively.

(vi) The use of RSM is effective in identifying the relationship between different uncertain parameters (responses) with multiple inputs criterions (variables). 


\section{References}

[1] Alam, Md. A., Habib, Md. Z, Sheikh, Md. R. and Hasan, A. "A Study on the Quality of Concrete Production in Dhaka City",IOSR Journal of Mechanical and Civil Engineering (IOSR-JMCE), Vol. 13, Number 3, 2016, pp 89-98.

[2] Shetty,M.S.Concrete Technology, Ram Nagar, New Delhi, S.Chand, 2005.

[3] Zhang, H., Ma, S. and Wu, Y. Building Materials in Civil Engineering, Woodhead Publishing, 1518 Walnut Street, Suite 1100, Philadelphia, USA, 2010.

[4] Saikia, N. and de Brito, J. "Mechanical Properties and Abrasion Behaviour of Concrete containing Shredded PET Bottle Waste as a Partial Substitution of Natural Aggregate", Construction and Building Materials, Vol. 52, 2015, pp 236-244.

[5] Kheder, G.F., Al-Gabban, A.M. and Suhad, M.A. "Mathematical Model for the Prediction of Cement Compressive Strength at the Ages of 7 and 28 Days within 24 Hours", Structures, Vol. 36, 2003, pp 693-701.

[6] Viviani, M., Glisic, B., Scrivener, K.L. and Smith, I.F.C. "Equivalency Points: Predicting Concrete Compressive Strength Evolution in Three Days. Cement Concrete Research, Vol. 38, 2008,pp. 10701078.

[7] Kabir, A., Hasan, M. and Miah, Md. K. "Strength Prediction Model for Concrete",ACEE International Journal on Civil and Environmental Engineering, Vol. 2, Number 1, 2013, pp 14-19, DOI: 01.IJCEE.2.1.1002.

[8] Zain, M.F.M., Suhad, M. Abd-Hamid, R. and Jamil, M. "Potential for Utilizing Concrete Mix Properties to Predict Strength at Different Ages. Journal of Applied Sciences, Vol. 10, Number 22, 2010, pp 2831-2838.

[9] Zain, M.F.M. and Abd, S.M. "Multiple Regression Models for Compressive Strength Prediction of
High-Performance Concrete", Journal of Applied Sciences, VOL. 9,2009, pp 155-160.

[10] Vahid, K.A. and Mohammad, T. "Prediction of 28-day compressive strength of concrete on the third day using artificial neural networks", International Journal of Engineering, Vol. 3, 2010, pp 565-575.

[11] Hasan, M.“Concrete Mix Design using Artificial Neural Network", Unpublished Bachelor of Engineering thesis, Department of Civil Engineering, Bangladesh University of Engineering and Technology, Dhaka, Bangladesh, 2012.

[12] Yu, C., Huang, L., Kuan, I. and Lee, S. "Optimized Production of Biodiesel from Waste Cooking Oil by Lipase Immobilized on Magnetic Nanoparticles", International Journal Molecular Sciences, Vol. 14, 2013, pp 24074-24086.

[13] Myers, R. H., Montgomery, D. C. and Andersoncook, C.M. Response Surface Methodology: Process and Product Optimization Using Designed Experiment, $4^{\text {th }}$ edition, John Wiley \& Sons, Inc., Hoboken, New Jersey, 2016.

[14] Muhammed B.S., Achara, B.E., Liew, M.S., Alaloul, W.S. and Khed, V. C. "Effects of Elevated Temperature on the Tensile Properties of NS-modified Self-Consolidating Engineered Cementitious Composites and Property Optimization using Response Surface Methodology (RSM)", Construction and Building Materials, Vol. 206, 2019, pp 449-469.

[15] Kamal, I., Sherwani, A.F., Ali, A., Khalid, A., Saadi, I. and Harbi, A. "Walnut Shell for Partial Replacement of Fine Aggregate in Concrete: Modeling and Optimization", Journal of Civil Engineering Research, Vol. 7, Number 4, 2017, 109-119. DOI: 10.5923/j.jce.20170704.01.

[16] Umasabor, R.I. "Evaluation of Curing Methods and Periwinkle Shell concrete using Response Surface Methodology", SN Applied Sciences", Vol. 1, Number 771, 2019, pp 1-6. 
[17] Raheem, A. A. and Kareem, M. A. "Optimal Raw Material Mix for the Production of Rice Husk Ash Blended Cement", International Journal of Sustainable Construction Engineering and Technology, Vol. 7, Number 2, 2017, pp 77-93.

[18] BS 12. Specification for Portland cement, London, British Stand Institution, 1996.

[19] Tijani, M.A., Ajagbe, W.O. and Agede, O.A. "Modelling the Effect of Burning Temperature and Time on Chemical Composition of Sorghum Husk Ash for Optimum Pozzolanic Activity", Journal of Engineering and Engineering Technology (FUTAJEET), Vol. 12, Number 2, 2018, pp 273-281.

[20] BS1881: Part 116. Method for determination of compressive strength of concrete cubes, London: British Standard Institution, 1983.

[21] BS 812: Part 2. Testing Aggregates: Methods for Determination of Density, London, British Standard Institution, 1995.

[22] Kozul, R. and Darwin, D. "Effects of Aggregate Type, Size and Content on Concrete Strength and Fracture Energy" Structural Engineering and Engineering Materials SM Report No.43. University of Kansas Center for Research, Inc. Lawrence, Kansas, 1997.

[23] Okonkwo, V.O. and Emmanuel, E. "Effects of Aggregate Gradation on the Properties of Concrete Made from Granite Chippings", International Journal of Advancements in Research and Technology, Vol. 4, Number 12, 2015, pp 17-20.

[24] Singh, M. and Siddique, R. "Effect of Coal Bottom Ash as Partial Replacement of Sand on Properties of Concrete", Conservation and Recycling, Vol. 72, 2013, pp 20-32 